\title{
Structure-Based Design and Synthesis of Fluorescent PPAR $\alpha / \delta$ Co-agonist and Its Application as a Probe for Fluorescent Polarization Assay of PPAR $\delta$ Ligands
}

\author{
Yoko Araya, ${ }^{a}$ Jun-ichi Kasuga, ${ }^{a}$ Kenji Toyota, ${ }^{b}$ Yuko Hirakawa, ${ }^{b}$ Takuji Oyama, ${ }^{b}$ \\ Makoto Makishima, ${ }^{c}$ Kosuke Morikawa, ${ }^{b}$ Yuichi Hashimoto, ${ }^{a}$ and Hiroyuki MiYachi ${ }^{*}, a$ \\ ${ }^{a}$ Institute of Molecular and Cellular Biosciences, University of Tokyo; Yayoi, Bunkyo-ku, Tokyo 113-0032, Japan: ${ }^{b}$ The \\ Takara-Bio Endowed Division, Institute for Protein Research, Osaka University; 6-2-3 Furuedai, Suita, Osaka 565-0874, \\ Japan: and ${ }^{c}$ School of Medicine, Nihon University; 30-1 Oyaguchi-kamicho, Itabashi-ku, Tokyo 173-8610, Japan. \\ Received May 20, 2008; accepted June 18, 2008
}

Based on the result of X-ray crystallographic analysis of our peroxisome proliferator-activated receptor alpha and delta (PPAR $\alpha / \delta$ ) co-agonist complexed with human PPAR ligand binding domain (LBD), we designed and synthesized an optically active fluorescent $\operatorname{PPAR} \alpha / \delta$ co-agonist, which has a pyrene unit incorporated directly at the hydrophobic tail part of the structure as a fluorophore. This fluorescent co-agonist was applied in a homogeneous fluorescent polarization assay format for the identification of PPAR $\delta$ ligands.

Key words fluorescent ligand; phenylpropanoic acid; fluorescent polarization; peroxisome proliferator-activated receptor; fluorescent peroxisome proliferator-activated receptor $\alpha / \delta$ co-agonist

Peroxisome proliferator-activated receptors (PPARs) are nuclear receptors with pleiotropic biological functions that include regulatory roles in lipid, lipoprotein and glucose homeostasis. PPARs are activated by endogenous saturated and unsaturated fatty acids and their metabolites and synthetic ligands. ${ }^{1)}$ Three subtypes have been isolated to date: $\operatorname{PPAR} \alpha(\mathrm{NR} 1 \mathrm{C} 1), \operatorname{PPAR} \delta$ (NR1C2) and PPAR $\gamma(\mathrm{NR} 1 \mathrm{C} 3)$. $\operatorname{PPAR} \alpha$ is mostly expressed in tissues involved in lipid oxidation, such as liver, kidney, skeletal, cardiac muscle and adrenal glands. ${ }^{2)}$ PPAR $\gamma$ is expressed in adipose tissue, macrophages and vascular smooth muscles. ${ }^{3)}$ In contrast to the specific distributions of $\operatorname{PPAR} \alpha$ and $\operatorname{PPAR} \gamma, \operatorname{PPAR} \delta$ is ubiquitously expressed. ${ }^{4)}$

Two of these subtypes are the molecular targets of drugs used for the treatment of dyslipidemia and type II diabetes mellitus, i.e., the dyslipidemic fibrate class of compounds are agonists of PPAR $\alpha$, while the insulin-sensitising glitazones are agonists of PPAR $\gamma$. On the other hand, $\operatorname{PPAR} \delta$ is the least well investigated subtype. However, the availability of $\operatorname{PPAR} \delta$ knockout animals and selective ligands prompted us to examine the involvement of PPAR $\delta$ in fatty acid metabolism, insulin resistance, reverse cholesterol transport, and inflammation. Activation of PPAR $\delta$ was reported to improve glucose tolerance and insulin resistance in ob/ob mice. Consequently, there is increasing interest in this receptor as a target for drug development.
As a part of our continuing research directed toward the structural development of characteristically subtype-selective PPAR agonists, we required a rapid and simple method to determine PPAR $\delta$ binding activity without using isotope-labeled material(s). Here, we report the design and the synthesis of a fluorescent PPAR $\alpha / \delta$ co-agonist, suitable for use in a homogeneous fluorescent polarization assay format for the identification of both endogenous and exogenous PPAR $\delta$ ligands. Perterson and co-worker have designed and synthesized a fluorescent PPAR $\gamma$ agonist, based on GlaxoSmithKline (GSK)'s potent PPAR $\gamma$ agonist farglitazar, for high-throughput screening of PPAR $\gamma$ ligands. ${ }^{5)}$ However, their ligand might not be suitable for the screening of other PPAR subtypes, such as PPAR $\delta$, because the PPAR $\gamma$-selectivity of the mother compound, farglitazar, is extremely high (more than 1000 -fold selectivity for PPAR $\gamma$ over $\operatorname{PPAR} \alpha$ or $\operatorname{PPAR} \delta$ ).

Previously, we designed and synthesized a potent and human PPAR $\alpha / \delta$ co-agonist, TIPP-401 (2), based on KCL (1), a PPAR $\alpha$-selective agonist, as a lead compound (Fig. 1A). ${ }^{6}$ We have solved the X-ray crystallographic structure of TIPP-401 complexed with human PPAR $\delta$ ligand binding domain at $2.7 \mathrm{~A}$ resolution (Fig. 1B) (The Protein Data Bank code for the PPAR $\delta$ /TIPP-401 complex is 2ZNQ). The PPAR ligand-binding pocket is reported to form a large Y-shaped cavity that extends from the $\mathrm{C}$-terminal helix to the $\beta$-sheet lying between helices $\mathrm{H} 3$ and $\mathrm{H} 6{ }^{7)}$ We confirmed the pres-
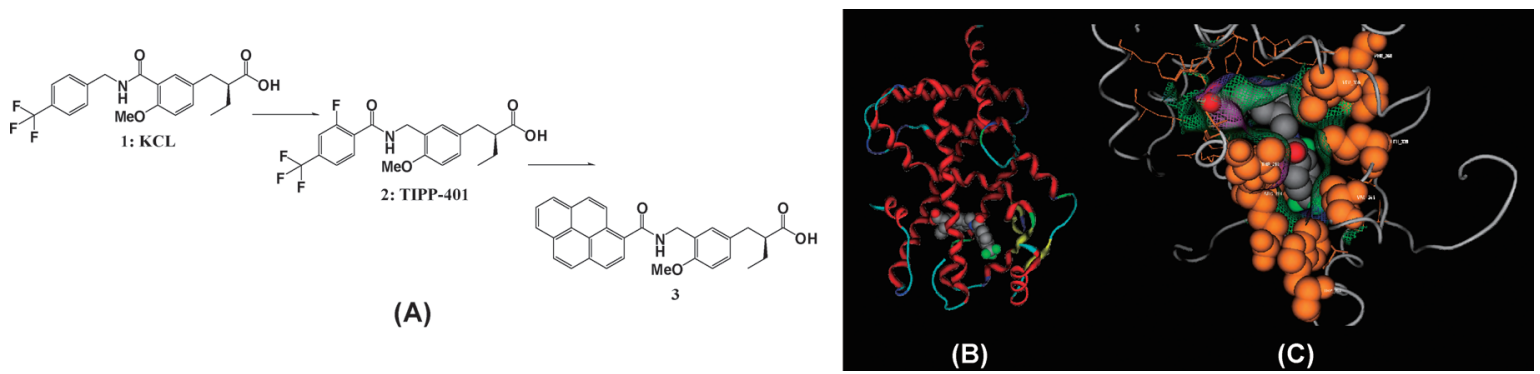

Fig. 1. (A) Structures of KCL and TIPP-401, (B) an Overview of the Structure of TIPP-401 Complexed with hPPAR $\delta$ Ligand Binding Domain (LBD) and (C) Zoomed View of the Hydrophobic Tail Part of TIPP-401 


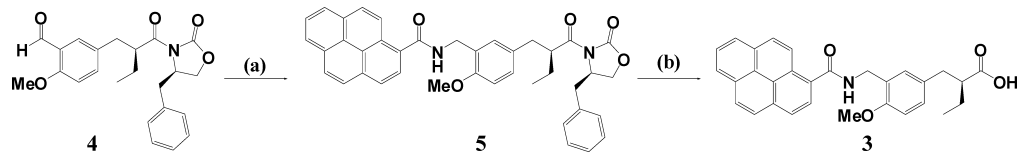

Reagents and conditions; a) pyrene-1-carboxamide, triethylsilane, trifluoroacetic acid, toluene, reflux, $24 \mathrm{~h}, 70 \%$; $) \mathrm{LiOH} \mathrm{H}_{2} \mathrm{O}, 30 \% \mathrm{H}_{2} \mathrm{O}_{2}, \mathrm{THF}: \mathrm{H}_{2} \mathrm{O}=4: 1(\mathrm{v} / \mathrm{v}), 0{ }^{\circ} \mathrm{C}, 85 \%$.

Chart 1. Synthetic Route to Fluorescent $\operatorname{PPAR} \alpha / \delta$ Co-agonist

ence of the cavity in our structure, and found that the hydrophobic tail part, the 2-fluoro-4-trifluoromethylphenyl group, of TIPP-401, is located in the narrow bottom cavity of the Y-shaped pocket composed of Trp264, Val281, Phe282, Arg284, Leu339, Val341 and Val348 (Fig. 1C). The depth of the bottom cavity is limited by a wall composed of the bulkier side chains of Trp264 and Arg284. Based on these insights, we anticipated that a structurally planar and smaller fluorophore, pyrene, could be incorporated directly as a hydrophobic tail part of the molecule to afford a fluorescent PPAR agonist without losing the potent PPAR $\alpha / \delta$ co-agonist nature.

Chemistry The benzaldehyde derivative $4^{8)}$ was amidealkylated $^{9)}$ with pyrene-1-carboxamide (5), followed by removal of the chiral auxiliary to afford the desired $(S)$-configuration product, 3 (Chart 1$){ }^{10)}$ The antipodal $(R)$ enantiomer was prepared via similar procedures, using $(S)$ - $N$-butyryl-4benzyloxazolidinone as the reagent.

\section{Results and Discussion}

As expected, $(S)$-3 exhibits PPAR $\alpha / \delta$ co-agonistic activity as potent as that of TIPP-401, while the PPAR $\gamma$ agonistic activity is weak. The $\mathrm{EC}_{50} \mathrm{~S}(\mathrm{nM})$ towards PPAR $\delta / \operatorname{PPAR} \alpha /$ PPAR $\gamma$ were $40 / 10 />10000$ for $(S)-3,400 / 100 />10000$ for $(R)-3$, and 24/10/2200 for TIPP-401 in our assay system (the $\mathrm{EC}_{50}$ values were derived by curve-fitting using Origin ${ }^{\circledR}$ software (Origin Lab)). Clear enantio-dependency of the transactivation activity towards the PPAR subtypes was also found, and $(S)$-3 exhibited more potent PPAR $\alpha / \delta$ transactivation activity than the antipodal $R$ isomer, $(R)-3$. Thus, we obtained a fluorescent $\operatorname{PPAR} \alpha / \delta$ co-agonist by introducing a pyrene group as a fluorophore directly in place of the 2-fluoro-4-trifluoromethylphenyl group of TIPP-401 (2).

In order to investigate the utility of $(S)-\mathbf{3}$ as a fluorescent probe, the dependence of the spectroscopic properties upon the polarity of the solvent was examined. We found, that the physicochemical properties were not greatly affected by the solvent polarity, i.e., the excitation maxima and the emission maxima of $(S)-3$ are $350 \mathrm{~nm}$ and $399 \mathrm{~nm}$ in phosphate buffer saline (PBS) containing $0.1 \%$ DMSO and $354 \mathrm{~nm}$ and $394 \mathrm{~nm}$ in $\mathrm{CH}_{2} \mathrm{Cl}_{2}$, respectively.

To examine the binding of PPAR $\alpha$ and $\operatorname{PPAR} \delta$ to this fluorescent probe, the human PPAR $\alpha$ (or human $\operatorname{PPAR} \delta$ ) ligand binding domain (LBD) was added to PBS containing $(S)-3$ at the concentration of $100 \mathrm{~nm}$ (this concentration provides sufficient fluorescence polarization). In both cases, saturation of binding to the PPAR LBD was obtained (Figs. 2A, B), and the affinity constants $\left(K_{\mathrm{d}}\right)$ were determined to be $97 \mathrm{~nm}$ and $120 \mathrm{~nm}$, respectively (The $K_{\mathrm{d}}$ values of the tested compounds were derived by curve-fitting using Origin ${ }$ software (Origin Lab.)). On the other hand, the binding was not saturated in the case of human PPAR $\gamma$ LBD, even when 1000-fold excess of $(S)$-3 was used, and the affinity constant $\left(K_{\mathrm{d}}\right)$ appeared to
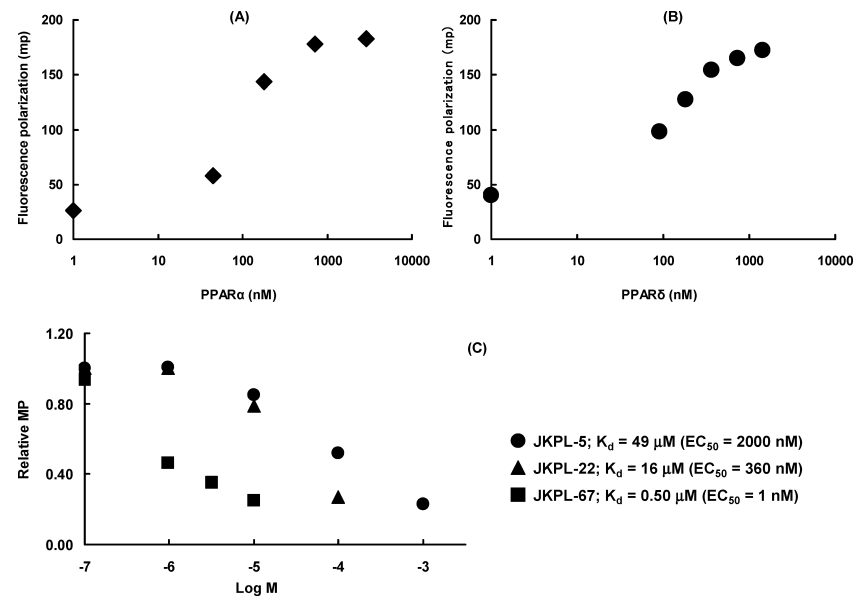

Fig. 2. Fluorescence Polarization Changes upon Addition of hPPAR $\alpha(\mathrm{A})$ and hPPAR $\delta(\mathrm{B})$ to $(S)-3$ (100 nM) in PBS and (C) the Dose-Response Relationships of the Binding of Representative Compounds to PPAR $\delta$

be more than $1000 \mathrm{~nm}$ (data not shown). Based on these experiments, the optimal $\operatorname{PPAR} \alpha$ and $\operatorname{PPAR} \delta$ LBD concentration for subsequent competition binding experiments was determined to be $500 \mathrm{~nm}$ in both cases.

Thus, we have successfully constructed a homogeneous fluorescent polarization assay method for measuring the binding of test compounds with $\operatorname{PPAR} \delta$. Using this method, we reevaluated our synthetic PPAR $\delta$ ligands (JKPL-5, JKPL22, and JKPL-67). The PPAR $\delta$ agonistic activities of these compounds had previously been evaluated by means of a functional biochemical method of transactivation assay, but the binding abilities remained uncertain. As shown in Fig. $2 \mathrm{C}$, the dose-dependent decrease in the relative fluorescent polarization values indicates that these compounds bind PPAR $\delta$ dose-dependently. The rank order of the binding activity was JKPL-5 $<$ JKPL-22 $<$ JKPL-67, which is consistent with the rank order of functional PPAR $\delta$ transactivation activity. These results confirm the usefulness of the present assay method.

Then, we applied this method to evaluate the binding ability of naturally occuring fatty acid derivatives. n-3 Polyunsaturated fatty acids (PUFA), such as eicosapentaenoic acid (EPA) and docosahexaenoic acid (DHA), have been reported to improve lipid profiles, ${ }^{11)}$ reduce blood pressure, ${ }^{12)}$ improve insulin resistance, ${ }^{13)}$ and so on. These beneficial pharmacological effects of EPA and DHA are thought to be mediated through binding to and activating PPARs, especially PPAR $\alpha$ and PPAR $\gamma$. We hypothesize that $\operatorname{PPAR} \delta$ binding and activation also contribute to the effects of PUFA. The results are summarized in Fig. 3. As expected, the PUFAs tested bind dose-dependently to PPAR $\delta$. We found that the binding was independent of the degree of unsaturation of the fatty acids, although saturated fatty acids tested did not exhibit signifi- 

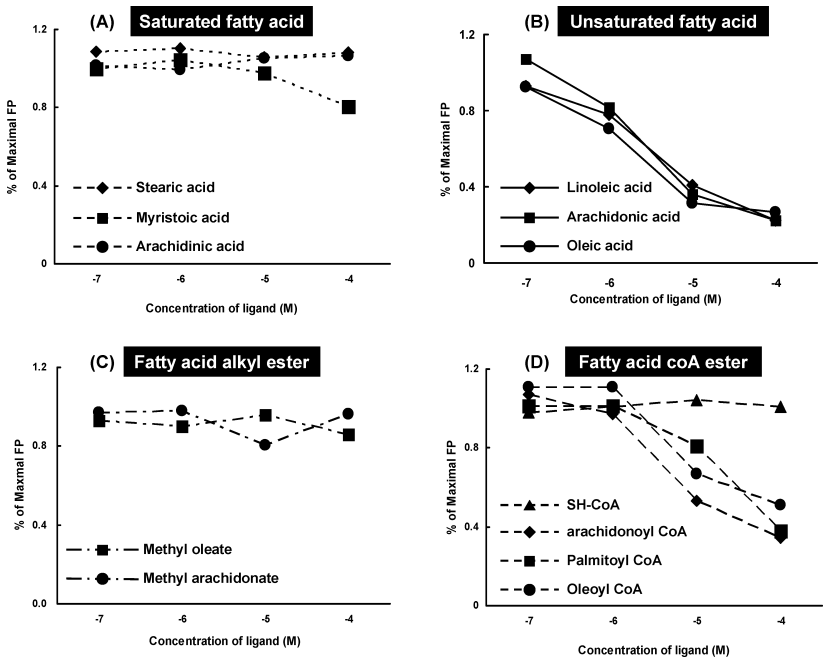

Fig. 3. Dose-Response Relationships of the Fluorescence Polarization of Fatty Acid Derivatives

cant binding at the concentration of $100 \mu \mathrm{M}$. The binding ability of the PUFAs was lost upon methyl esterification, but interestingly, acyl-CoA esterification restored the binding ability. All the acyl-CoA ester derivatives of PUFAs tested bound dose-dependently to PPAR $\delta$ independently of the degree of unsaturation of the PUFAs. These results are consistent with our hypothesis the beneficial pharmacological effects of PUFAs are mediated through binding to and activating all PPAR subtypes.

In summary, we have developed a fluorescent $\operatorname{PPAR} \alpha / \delta$ co-agonist suitable for use in a homogeneous fluorescent polarization assay format for the screening of $\operatorname{PPAR} \delta$ ligands. The optimization of the assay format and its application to find structurally new PPAR $\delta$ ligands among compounds of natural or synthetic origin is in progress.

\section{Experimental}

Melting points were determined by using a Yanagimoto hot-stage melting point apparatus and are uncorrected. Elemental analyses were carried out in the Microanalytical Laboratory, Faculty of Pharmaceutical Sciences, University of Tokyo, and were within plus or minus $0.3 \%$ of the theoretical values. NMR spectra were recorded on a JEOL JNM-GX500 (500 MHz) spectrometer. Chemical shifts are expressed in ppm relative to tetramethylsilane. Mass spectra were recorded on a JEOL JMS-DX303 spectrometer.

Preparation of (S)-2-(4-Methoxy-3-((pyrene-1-carboxamido)methyl)benzyl)butanoic Acid A mixture of $4(187 \mathrm{mg}, 0.47 \mathrm{mmol})$, pyren-1-ylcarboxamide $(348 \mathrm{mg}, 1.42 \mathrm{mmol})$, triethylsilane $(0.20 \mathrm{ml}, 1.42 \mathrm{mmol})$, trifluoroacetic acid $(0.10 \mathrm{ml}, 1.42 \mathrm{mmol})$, and $30 \mathrm{ml}$ of dehydrated toluene was refluxed overnight. The mixture was evaporated, and the residue was purified by silica gel column chromatography (eluant; $n$-hexane : ethyl acetate $=2: 1$ $\mathrm{v} / \mathrm{v})$ to obtain $218 \mathrm{mg}(74 \%)$ of the intermediate 5 as a colorless oil. The intermediate $5(210 \mathrm{mg}, 0.34 \mathrm{mmol})$ was dissolved in $20 \mathrm{ml}$ of a mixed solvent of tetrahydrofuran and water $(4: 1 \mathrm{v} / \mathrm{v})$, under an argon atmosphere with ice-cooling. To this solution was added $30 \%$ aqueous hydrogen peroxide $(0.17 \mathrm{ml}, 1.50 \mathrm{mmol})$. Then lithium hydroxide monohydrate $(21.0 \mathrm{mg}$, $0.50 \mathrm{mmol}$ ) was added, and the mixture was stirred overnight under ice-cooling. Sodium hydrogen sulfite solution was added dropwise. The reaction mixture was concentrated, poured into ice water, acidified with $5 \% \mathrm{HCl}$. The whole was extracted with ethyl acetate, washed with water and brine, dried over anhydrous magnesium sulfate and concentrated. The residue was purified by silica gel column chromatography (eluant; $n$-hexane: ethyl acetate $=2: 3 \mathrm{v} / \mathrm{v})$ to afford $104 \mathrm{mg}(67 \%)$ of the title compound as a colorless crystals; ${ }^{1} \mathrm{H}-\mathrm{NMR}\left(500 \mathrm{MHz}, \mathrm{CDCl}_{3}\right) \delta 8.46(\mathrm{~d}, 1 \mathrm{H}, J=9.4 \mathrm{~Hz}), 8.17$ $(\mathrm{m}, 2 \mathrm{H}), 7.98(\mathrm{~m}, 5 \mathrm{H}), 7.32(\mathrm{~s}, 1 \mathrm{H}), 7.10(\mathrm{~d}, 1 \mathrm{H}, J=5.6 \mathrm{~Hz}), 6.80(\mathrm{~d}, 1 \mathrm{H}$, $J=5.6 \mathrm{~Hz}), 6.63(\mathrm{~m}, 1 \mathrm{H}), 4.70(\mathrm{~m}, 2 \mathrm{H}), 3.82(\mathrm{~s}, 3 \mathrm{H}), 2.87(\mathrm{~m}, 1 \mathrm{H}), 2.74(\mathrm{~m}$, $1 \mathrm{H}), 2.56(\mathrm{~m}, 1 \mathrm{H}), 1.50(\mathrm{~m}, 2 \mathrm{H}), 0.94(\mathrm{t}, 3 \mathrm{H}, J=7.5 \mathrm{~Hz}) ; \mathrm{HR}-\mathrm{MS} ;(\mathrm{M}+\mathrm{H})^{+}$ Calcd for $\mathrm{C}_{30} \mathrm{H}_{27} \mathrm{NO}_{4}, 466.2018$, Found 466.2029; Anal. Calcd for $\mathrm{C}_{30} \mathrm{H}_{27} \mathrm{NO}_{4}: \mathrm{C}, 77.40 ; \mathrm{H}, 5.85 ; \mathrm{N}, 3.01$. Found: $\mathrm{C}, 77.24 ; \mathrm{H}, 6.07 ; \mathrm{N}, 3.00$; $[\alpha]_{\mathrm{D}} 24.6^{\circ}(c=0.20, \mathrm{MeCN})$.

Fluorescence Polarization Assays Assays employed compound (S)-3 (conc. $=500 \mathrm{nM}$ ) in binding buffer $\left(10 \mathrm{~mm}\right.$ HEPES, $\mathrm{MgCl}_{2} 2 \mathrm{~mm}, \mathrm{NaCl}$ $150 \mathrm{~mm}$, HEPES $10 \mathrm{~mm}$, DTT $5 \mathrm{~mm}$ pH 7.3). The data shown in Figs. 2 and 3 were obtained with a JASCO spectrofluorometer FP-6500. The $K_{\mathrm{d}}$ values were calculated by nonlinear least squares curve fitting using binding models from ORIGIN ${ }^{\mathbb{B}}$ (lightstone Corp., Japan).

Acknowledgement The work described in this paper was partially supported by Grants-in-Aid for Scientific Research from The Ministry of Education, Culture, Sports, Science and Technology of Japan.

\section{References}

1) Alberti K. G., Zimmet P. Z., Diabet. Med., 15, 539-553 (1998).

2) Mukherjee R., Jow L., Noonan D., McDonnell D. P., J. Steroid Biochem. Mol. Biol., 51, 157-166 (1994).

3) Okuno A., Tamemoto H., Tobe K., Ueki K., Mori Y., Iwamoto K., Umesono K., Akanuma Y., Fujiwara T., Horikoshi H., Yazaki Y., Kadowaki T., J. Clin. Invest., 101, 1354-1361 (1998).

4) Willson T. M., Brown P. J., Sternbach D. D., J. Med. Chem., 43, 527$550(2000)$.

5) DeGrazia M. L., Thompson J., Vanden Heuvel J. P., Peterson B. R., Bioorg. Med. Chem., 11, 4325- 4332 (2003).

6) Kasuga J., Makishima M., Hashimoto Y., Miyachi H., Bioorg. Med. Chem. Lett., 16, 554-558 (2006).

7) Nolte R. T., Wisely G. B., Westin S., Cobb J. E., Lambert M. H., Kurokawa R., Rosenfeld M. G., Willson T. M., Glass C. K., Milburn M. V., Nature (London), 395, 137-143 (1998).

8) Kasuga J., Hashimoto Y., Miyachi H., Bioorg. Med. Chem. Lett., 16, $771-774$ (2006).

9) Dube D., Scholte A. A., Tetrahedron Lett., 40, 2295-2298 (1999).

10) Kasuga J., Yamasaki D., Araya Y., Nakagawa A., Makishima M., Doi T., Hashimoto Y., Miyachi H., Bioorg. Med. Chem., 14, 8405-8414 (2006).

11) Mori T. A., Burke V., Puddey I. B., Watts G. F., O'Neal D. N., Best J. D., Beilin L. J., Am. J. Clin. Nutr., 71, 1085-1094 (2000).

12) Prisco D., Paniccia R., Bandinelli B., Filippini M., Francalanci I., Giusti B., Giurlani L., Gensini G. F., Abbate R., Neri Serneri G. G., Thromb. Res., 91, 105-112 (1998).

13) Holness M. J., Greenwood G., Smith N., Sugden M., Endocrinology, 144, 3958-3968 (2003). 